\title{
Congestive Heart Failure: Diagnosis and Management in Primary Health Care
}

\author{
Ibrahim Abdulrahman Altukhays ${ }^{1 \star}$, Salman Hejab Alosaimi ${ }^{1}$, Meshari Assaf Alotaibi ${ }^{1}$, Amirh Ayman Zamzami ${ }^{2}$, Zainab Adel Slais ${ }^{2}$, \\ Amani Mohammed Al Zainaldeen ${ }^{2}$, Laila Hassan Hakami ${ }^{3}$, Badria Fahad Al Saber ${ }^{3}$, Ahmed Sanad Ibrahim Alrashidi ${ }^{4}$, Khaled \\ Soud Alraddadi ${ }^{4}$, Maitham Ahmed Alfardan ${ }^{5}$, Mohammed Abdulrahman Alotaibi ${ }^{6}$
}

${ }^{1}$ Department of Family Medicine, Dwadmi Hospital, Dwadmi, KSA. ${ }^{2}$ Faculty of Medicine, Medical University of Lodz, Lodz, Poland. ${ }^{3}$ Faculty of Medicine, King Khaled Hospital, Al-Kharj, KSA. ${ }^{4}$ MBBS, King Salman Bin Abdulaziz Medical City, Madina, KSA. ${ }^{5}$ Emergency Department, Oyun Central Hospital, Al Ahsa, KSA. ${ }^{6}$ Faculty of Medicine, Shaqra University, Shaqra, KSA.

\section{Abstract}

Heart failure disease has been one of the major chronic cardiovascular diseases that cause morbidity, mortality, and hospitalization of all cardiac patients. Heart failure has a significantly increased lifetime risk of development is about $20 \%$. Symptomatic predictions are usually non-specific and hardly can discriminate the occurrence of heart failure from other diseases. It represents a challenging problem because of its economical and medical burden on the health care system. However, the management and presentation of a patient with heart failure remain in the fields of doubt. This review will highlight the importance of diagnosing and managing Congestive heart failure patients for primary health care physicians. This review was collected and classified from eligible published English written documents, articles, clinical trials. This electronic research engine was included: PubMed. This review discussed the diagnosis and management of Congestive heart failure and the details regarding this topic including definitions classifications, were included in this review. The primary care physician approach is often concerned with traditional palliative therapies before worsening the condition and plans to assess different reports regarding heart failure patients throughout their follow-up schedules.

Keywords: Congestive heart failure, Diagnosis, Management, Prognosis, Primary health care

\section{INTRODUCTION}

Heart failure disease has been one of the major chronic cardiovascular diseases that cause morbidity, mortality, and hospitalization of all cardiac patients. Heart failure has a significantly increased lifetime risk of development is about $20 \%[1,2]$. Other studies estimated the overall lifetime risk percent according to gender, where men $33 \%$ are higher in developing heart failure than women $28 \%$ [3, 4]. Although, congestive heart failure prevalence differs according to the specific studied population. However, the estimated prevalence of heart failure is roughly $1-2 \%$ and might increase to $>10 \%$ among people over 70 of age $[4,5]$. Furthermore, there has been a remarkable escalation in the incidence of chronic cardiovascular diseases in recent decades [6, 7].

The final stage of various cardiac issues is usually congestive heart failure. It is represented as a challenging problem because of its economical and medical burden on the health care system. Understanding the pathological and physiological condition of congestive heart failure has improved over the past $20-30$ years, where new modalities for identifying therapies are developed $[4,8]$.

However, the management and presentation of a patient with heart failure remain in the fields of doubt. In this review, we will highlight the importance of diagnosing and managing Congestive heart failure patients for primary health care physicians.

Low-frequency neuromuscular stimulation is a safe and effective rehabilitation protocol that could partially reverse the abnormal response to exercise in advanced heart failure patients helping in their symptoms and improved activities [9].

In a study, Rano K. sinuraya et al. revealed that the Cost related to CVD in all primary health care centers in Bandung

Address for correspondence: Ibrahim Abdulrahman Altukhays, Department of Family Medicine, Dwadmi Hospital, Dwadmi, KSA. Abr.tk@ hotmail.com

This is an open-access article distributed under the terms of the Creative Commons Attribution-Non Commercial-Share Alike 3.0 License, which allows others to remix, tweak, and build upon the work non commercially, as long as the author is credited and the new creations are licensed under the identical terms.

How to cite this article: Altukhays I A, Alosaimi S H, Alotaibi M A, Aamzami A A, Slais Z A, Al Zainaldeen A M, et al. Congestive Heart Failure: Diagnosis and Management in Primary Health Care. Arch. Pharm. Pract. 2022;13(1):1-4. https://doi.org/10.51847/Kbs2ghpd1q 
is higher after the implementation of national health insurance [10].

\section{Materials and Methods}

This review was collected and classified from eligible published English written documents, articles, clinical trials. This electronic research engine was included: PubMed. The keywords "Congestive" 'Heart' and 'Failure' including words used in Mesh (((('Diagnosis' [Mesh])), (('Prognosis' [Mesh])), (('Management' [Mesh])), (('Primary' [Mesh])) were used in combinations. This review discussed the diagnosis and management of Congestive heart failure and the details regarding this topic including definitions classifications, were included in this review.

\section{Review}

\section{Diagnosis}

\section{Symptoms and Signs in Clinical Presentation}

The progression and prognostic assessment of congestive heart failure depend on the European Society of Cardiology (ESC) 2016 guidelines for diagnosing and treating acute and chronic heart failure and the American college of cardiology American heart association (ACC\AHA) [11]. Symptomatic predictions are usually non-specific and hardly can discriminate the occurrence of heart failure from other diseases. However, detection of the early signs of heart failure can be more specific, such as apical impulse displacement and jugular venous pressure elevation (Table 1) [11-13].

\begin{tabular}{cc}
\hline $\begin{array}{c}\text { Table 1. Symptoms and } \\
\text { presentation: }[11-13]\end{array}$ & Signs in Heart failure \\
\hline Symptoms & More specific \\
\hline Conventional symptoms & Jugular venous pressure elevation \\
Breathlessness & Hepatojugular reflux \\
Orthopnea & Gallop heart rhythm \\
Reduced exercise tolerance & Lateral apical impulse \\
displacement \\
Paroxysmal nocturnal dyspnea & \\
Tiredness, fatigability, more & \\
time for exercise recovery & Less specific \\
Swelling on the ankles & Weight gain \\
Less conventional & Sudden weight loss \\
Wheezing & Tissue wasting \\
Bloated feeling & Cardiac murmur \\
Nocturnal coughing & scrotal) \\
Loss of appetite & Peripheral oedema (Ankle, sacral, \\
Confusion & Pulmonary crepitations \\
Depression & Dullness to percussion and \\
Palpitations & reduced air entry \\
Dizziness & Tachycardia \\
Syncope & Cheyne Stokes respiration \\
Bendopnea & Hepatomegaly \\
&
\end{tabular}

Tachypnoea and Irregular pulse Ascites

Cold extremities Oliguria

Narrow pulse pressure

\section{Risk Factors and Prognosis}

In general, heart failure outcome is associated with many significant dependents and independent risk factors. Ethnicity is one of the major risk factors that affect the outcome of the diseases. The predictions of increased risk of deaths in Asian patients with heart failure differ from the European ones [1416]. Gender differences have often a greater impact impairing the quality of life in patients. In several studies, the overall lifetime risk percent according to gender were men $33 \%$ are higher in developing heart failure than women $28 \%[3,4]$. However, other studies introduced women to have a stronger probability to be affected by congestive heart failure than most men. Moreover, women have a greater probability of developing typical heart failure with preserved ejection fraction than men $[17,18]$. Compared to men women have different physiological features that are considered a strong risk factor for heart failure development (Table 2) [19].

\begin{tabular}{cc}
$\begin{array}{c}\text { Table 2. Women Characteristic } \\
\text { anatomical features in comparison to men: }[19]\end{array}$ \\
$\begin{array}{cc}\text { Physiological and Anatomical } \\
\text { features }\end{array}$ & $\begin{array}{c}\text { Women compared } \\
\text { to men }\end{array}$ \\
\hline Mass at the left ventricle & Lower \\
Apoptosis and cell turnovers & Lower \\
Blood pressure & Lower \\
Resting heart rate & Higher \\
Contractility & Greater \\
Catecholamine-mediated vasoconstriction & Less \\
Coronary vessel caliber & Smaller \\
\hline
\end{tabular}

Unplanned hospitalization of patients with heart failure, nominates marks of mortality, and recurrent hospitalization $[16,20,21]$. Cardiovascular and non-cardiovascular comorbid diseases play a sensitive role in maintaining the prognostic statements of congestive heart failure progression. These comorbidities highly impact the diagnosis and management of heart failure. Diabetes, anemia, and metabolic iron deficiency (Table 3) are often observed in congestive heart failure patients and are acknowledged to complication the prognostic assessment of heart failure.

Table 3. Heart failure impact on Anemia and iron deficiency [22]

\begin{tabular}{cc} 
Anemia & Iron deficiency \\
\hline Renal impairment & $\begin{array}{c}\text { Iron absorption impairment. } \\
\text { Malnutrition and iron intake } \\
\text { Chronic inflammatory disorder }\end{array}$ \\
\hline
\end{tabular}


Dysfunction of the Bone Marrow

Blood loss from the

Gastrointestinal area.

Sequestration due to impaired

Hemodilution

Iron deficiency anemia iron transition leading to Chronic inflammation.

Diabetes mellitus risk of presence might not worsen the survival rate after all, but it does interplay a significant role with the etiology that increases the risk of deaths in patients with heart failure. This depends on the duration, other comorbidities, and damaged organs (Table 4) [22, 23]. Diabetes type 2 is found to have strong mortality risks in heart failure patients compared with cardiac patients without diabetes [22, 24].

\begin{tabular}{|c|c|}
\hline $\begin{array}{l}\text { Cardiovascular } \\
\text { risk degree }\end{array}$ & Condition \\
\hline Very high & $\begin{array}{l}\text { - Existing cardiovascular disease and diabetes } \\
\text { accompanied by end-organ damage. } \\
\text { - Cardiovascular risk for more than } 3 \text { years } \\
\text { - Diabetes for more than } 20 \text { years }\end{array}$ \\
\hline High & $\begin{array}{c}\text { Diabetes for more than } 10 \text { years not associated } \\
\text { with organ damage, but with cardiovascular } \\
\text { risks. }\end{array}$ \\
\hline Moderate & $\begin{array}{c}\text { - Type } 1 \text { diabetes in patients more than } 35 \text { years } \\
\text { of age of a } 10 \text { years duration with no } \\
\text { cardiovascular risks. } \\
\text { - Type } 2 \text { diabetes in patients more than } 50 \text { years } \\
\text { of age of a 10years duration with no } \\
\text { cardiovascular risks. }\end{array}$ \\
\hline
\end{tabular}

\section{Practical Management of Congestive Heart Failure in Primary Healthcare}

In the practical management of congestive heart failure, patients might experience various levels of intense symptoms and signs underlying this condition. The primary care physician approach is often concerned with traditional palliative therapies before worsening the condition and plans to assess different reports regarding heart failure patients throughout their follow-up schedules. If the role of palliative care is ineffectual then a referral should be noted [25]. The (Table 5) below presents a brief idea about the practical management of heart failure with preserved ejection fraction [26].

\section{Table 5. Palliative management in heart failure with} preserved ejection fraction [26]

\section{Lowest effective dose of diuretics to monitor volume overload}

\section{Moderate restriction of Sodium diet}

Patient education on weight changes and how to maintain a perfect weight

Comprehensive counseling about follow up and management especially for newly hospitalized patients

Monitoring blood pressure, blood sugar, and other comorbidities Intensive heart rate control and sinus rhythm maintenance Treat myocardial ischemia

Sleep assessment for patients with suspected breathing disorders during the night or daytime excessive sleepiness

Follow up moderate regular physical activity

\section{Conclusion}

Heart failure has a significantly increased lifetime risk of development is about $20 \%$. The final stage of various cardiac issues is usually congestive heart failure. It is represented as a challenging problem because of its economical and medical burden on the health care system. Ethnicity and gender differences had often a greater impact impairing the quality of life in patients. However, the progression and prognostic assessment of congestive heart failure depend on the European Society of Cardiology (ESC) 2016 guidelines for diagnosing and treating acute and chronic heart failure and the American college of cardiologyl American heart association (ACC\AHA. In the practical management of congestive heart failure, patients might experience various levels of intense symptoms and signs underlying this condition. The primary care physician approach is often concerned with traditional palliative therapies before worsening the condition and plans to assess different reports regarding heart failure patients throughout their follow-up schedules. If the role of palliative care is ineffectual then a referral should be noted.

\section{ACKNOWLEDGMENTS: None CONFLICT OF INTEREST: None FINANCIAL SUPPORT: None ETHICS STATEMENT: None}

\section{REFERENCES}

1. Metra M, Teerlink JR. Heart failure. Lancet. 2017;390(10106):198195.

2. Rachamin Y, Meier R, Rosemann T, Flammer AJ, Chmiel C. Heart failure epidemiology and treatment in primary care: a retrospective cross-sectional study. ESC Heart Fail. 2021;8(1):489-97.

3. Bleumink GS, Knetsch AM, Sturkenboom MC, Straus SM, Hofman A, Deckers JW, et al. Quantifying the heart failure epidemic: prevalence, incidence rate, lifetime risk and prognosis of heart failure The Rotterdam Study. Eur Heart J. 2004;25(18):1614-9.

4. Kurmani S, Squire I. Acute Heart Failure: Definition, Classification and Epidemiology. Curr Heart Fail Rep. 2017;14(5):385-92.

5. Mosterd A, Hoes AW. Clinical epidemiology of heart failure. Heart. 2007;93(9):1137-46.

6. Mills KT, Bundy JD, Kelly TN, Reed JE, Kearney PM, Reynolds K, et al. Global Disparities of Hypertension Prevalence and Control: A Systematic Analysis of Population-Based Studies from 90 Countries. Circulation. 2016;134(6):441-50.

7. Kjeldsen SE, Naditch-Brule L, Perlini S, Zidek W, Farsang C. Increased prevalence of metabolic syndrome in uncontrolled hypertension across Europe: the Global Cardiometabolic Risk Profile in Patients with hypertension disease survey. J Hypertens. 2008;26(10):2064-70.

8. Skrzypek A, Mostowik M, Szeliga M, Wilczyńska-Golonka M, Dębicka-Dąbrowska D, Nessler J. Chronic heart failure in the elderly: still a current medical problem. Folia Med Cracov. 2018;58(4):47-56. 
9. Elmasry DM, Elnahas NG, Khorshid H, Rahmy AF. The effect of low frequency neuromuscular stimulation on sympathetic activity in advanced heart failure. J Adv Pharm Educ Res. 2019;9(4):29-35

10. Sinuraya RK, Rianti A, Suwantika AA. Cost minimization of cardiovascular disease (CVD) drugs in primary healthcare centers in Bandung, Indonesia. J Adv Pharm Educ Res. 2021;10(1):63-9.

11. Ponikowski P, Voors AA, Anker SD, Bueno H, Cleland JG, Coats AJ, et al. 2016 ESC Guidelines for the diagnosis and treatment of acute and chronic heart failure: The Task Force for the diagnosis and treatment of acute and chronic heart failure of the European Society of Cardiology (ESC). Developed with the special contribution of the Heart Failure Association (HFA) of the ESC. Eur J Heart Fail. 2016;18(8):891-975.

12. Kelder JC, Cramer MJ, van Wijngaarden J, van Tooren R, Mosterd A, Moons KG, et al. The diagnostic value of physical examination and additional testing in primary care patients with suspected heart failure. Circulation. 2011;124(25):2865-73.

13. Boonman-de Winter LJ, Rutten FH, Cramer MJ, Landman MJ, Zuithoff NP, Liem AH, et al. Efficiently screening heart failure in patients with type 2 diabetes. Eur J Heart Fail. 2015;17(2):187-95.

14. Nagai T, Sundaram V, Shoaib A, Shiraishi Y, Kohsaka S, Rothnie KJ, et al. Validation of U.S. mortality prediction models for hospitalized heart failure in the United Kingdom and Japan. Eur J Heart Fail. 2018;20(8):1179-90.

15. Cooper LB, Yap J, Tay WT, Teng TK, MacDonald M, Anand IS, et al. Multi-ethnic comparisons of diabetes in heart failure with reduced ejection fraction: insights from the HF-ACTION trial and the ASIANHF registry. Eur J Heart Fail. 2018;20(9):1281-9.

16. Tomasoni D, Adamo M, Lombardi CM, Metra M. Highlights in heart failure. ESC Heart Fail. 2019;6(6):1105-27.

17. Scardovi AB, Petruzzi M, Rosano A, Lucia AR, De Maria R. Heart failure phenotype in women. G Ital Cardiol (Rome). 2012;13(5 Suppl 1):6s-11s.
18. Sciomer S, Moscucci F, Salvioni E, Marchese G, Bussotti M, Corrà U, et al. Role of gender, age and BMI in prognosis of heart failure. Eur $\mathrm{J}$ Prev Cardiol. 2020;27(2_suppl):46-51.

19. Bozkurt B, Khalaf S. Heart Failure in Women. Methodist Debakey Cardiovasc J. 2017;13(4):216-23.

20. Solomon SD, Dobson J, Pocock S, Skali H, McMurray JJ, Granger CB, et al. Influence of nonfatal hospitalization for heart failure on subsequent mortality in patients with chronic heart failure. Circulation. 2007;116(13):1482-7.

21. Chioncel O, Mebazaa A, Harjola VP, Coats AJ, Piepoli MF, CrespoLeiro MG, et al. Clinical phenotypes and outcome of patients hospitalized for acute heart failure: the ESC Heart Failure Long-Term Registry. Eur J Heart Fail. 2017;19(10):1242-54.

22. Paolillo S, Scardovi AB, Campodonico J. Role of comorbidities in heart failure prognosis Part I: Anaemia, iron deficiency, diabetes, atrial fibrillation. Eur J Prev Cardiol. 2020;27(2_suppl):27-34.

23. Cosentino F, Grant PJ, Aboyans V, Bailey CJ, Ceriello A, Delgado V, et al. 2019 ESC Guidelines on diabetes, pre-diabetes, and cardiovascular diseases developed in collaboration with the EASD. Eur Heart J. 2020;41(2):255-323.

24. Rørth R, Jhund PS, Kristensen SL, Desai AS, Køber L, Rouleau JL, et al. The prognostic value of troponin $\mathrm{T}$ and $\mathrm{N}$-terminal pro B-type natriuretic peptide, alone and in combination, in heart failure patients with and without diabetes. Eur J Heart Fail. 2019;21(1):40-9.

25. Kavalieratos D, Gelfman LP, Tycon LE, Riegel B, Bekelman DB, Ikejiani DZ, et al. Palliative Care in Heart Failure: Rationale, Evidence, and Future Priorities. J Am Coll Cardiol. 2017;70(15):1919-30.

26. Upadhya B, Kitzman DW. Heart failure with preserved ejection fraction: new approaches to diagnosis and management. Clin Cardiol. 2020;43(2):145-55 